\title{
Identification of Phosphatidylcholine Isomers in Imaging Mass Spectrometry Using Gas-Phase Charge Inversion Ion/Ion Reactions
}

\author{
Jonathan T. Specker ${ }^{1}$, Steve L. Van Orden ${ }^{2}$, Mark E. Ridgeway ${ }^{2}$, Boone M. Prentice ${ }^{1 *}$ \\ ${ }^{1}$ Department of Chemistry, University of Florida, Gainesville, FL 32611 \\ ${ }^{2}$ Bruker Daltonics, Billerica, MA 01821
}

Running title: Identification of lipids in imaging mass spectrometry using ion/ion reactions

*Address correspondence to:
Dr. Boone M. Prentice
214 Leigh Hall
PO Box 117200
Department of Chemistry
University of Florida
Gainesville, FL 32611-7320
$\begin{array}{ll}\text { Phone: } \quad \text { (352) 392-0556 } \\ \text { Fax: } \quad \text { (352) 392-4651 } \\ \text { E-mail: } \quad \text { booneprentice@ chem.ufl.edu }\end{array}$ 


\begin{abstract}
Gas-phase ion/ion reactions have been enabled on a commercial dual source, hybrid QhFTICR mass spectrometer for use during imaging mass spectrometry experiments. These reactions allow for the transformation of the ion type most readily generated from the tissue surface to an ion type that gives improved chemical structural information upon tandem mass spectrometry (MS/MS) without manipulating the tissue sample. This process is demonstrated via the charge inversion reaction of phosphatidylcholine (PC) lipid cations generated from rat brain tissue via matrix-assisted laser desorption/ionization (MALDI) with 1,4-phenylenedipropionic acid (PDPA) reagent dianions generated via electrospray ionization (ESI). Collision induced dissociation (CID) of the resulting demethylated PC product anions allows for the determination of the lipid fatty acyl tail identities and positions, which is not possible via CID of the precursor lipid cations. The abundance of lipid isomers revealed by this workflow is found to vary significantly in different regions of the brain. As each isoform may have a unique cellular function, these results underscore the importance of accurately separating and identifying the many isobaric and isomeric lipids and metabolites that can complicate image interpretation and spectral analysis.
\end{abstract}




\section{INTRODUCTION}

There remain many instances in metabolomics and lipidomics studies where conventional mass spectrometry approaches do not provide sufficient structural characterization for biomolecules of interest. ${ }^{1-5}$ The challenge of poor specificity is due to several factors. First, there are often multiple peaks present at the same nominal mass that can be difficult to separate without a high resolution mass spectrometer. Second, each peak is often comprised of multiple structural isomers, which cannot be separated based on mass alone. Both of these factors result in increased spectral complexity and complicate data analysis and interpretation. Finally, the structural information obtained from a tandem mass spectrometry (MS/MS or $\mathrm{MS}^{\mathrm{n}}$ ) experiment is often not sufficient to completely characterize the compound of interest. These challenges are further complicated in imaging mass spectrometry (IMS), where ions are directly produced and sampled from the tissue surface..$^{6-8}$ Interfering compounds present at both nominal (i.e., isobaric) and exact (i.e., isomeric) mass-to-charge $(\mathrm{m} / \mathrm{z})$ ratios can result in the spatial distribution of an image representing not the spatial distribution of a single compound, but rather representing the confluence of several compounds that have overlapping $\mathrm{m} / \mathrm{z}$ values, resulting in inaccurate depictions of molecular distributions.

In order to improve analyte identification, a number of technologies have been developed for use in imaging mass spectrometry workflows. Upfront, condensed phase chromatographic separations are commonly used to improve analytical MS performance, but are usually incompatible with imaging time scales and/or sampling methods. ${ }^{9-13}$ High resolution accurate mass (HRAM) experiments can allow for $\mathrm{m} / \mathrm{z}$ measurements with better than parts per million (ppm) mass accuracies. ${ }^{14,} 15$ This can provide for the identification of a compound's elemental composition and the separation of isobaric contaminants. ${ }^{16}$ However, instruments with these 
capabilities tend to be more expensive and require long mass analysis times (e.g., orbitrap and Fourier transform ion cyclotron resonance [FT-ICR] mass spectrometers). Additionally, HRAM measurements do not provide any information about the orientation of chemical bonds and cannot distinguish between structural isomers. In some IMS applications, technologies such as ion mobility mass spectrometry (IM-MS) can separate compounds of similar $m / z$, ratios so long as their collision cross sections differ, ${ }^{17-22}$ but this is not always successful. While ion mobility can provide information on gas-phase conformations, it is difficult to obtain detailed primary structure information from these measurements. Tandem mass spectrometry approaches are often used to provide higher levels of specificity and structural information by fragmenting ions of interest and then analyzing the product ion masses. ${ }^{23-27}$ Collision induced dissociation (CID) is the most common form of tandem mass spectrometry and is available on most commercial instruments, but CID does not always provide sufficient structural information. For example, it is challenging to identify phosphatidylcholine (PC) lipids beyond the sum composition level (i.e., the total number of carbon atoms and degrees of unsaturation in the fatty acyl chains, expressed as TC:DB) directly from tissue in imaging mass spectrometry experiments. While readily abundant in positive ion mode IMS, CID of protonated PC ions typically results exclusively in fragmentation of the choline head group and gives no information on the fatty acyl chains. ${ }^{28}$ While negative ion mode CID results in fragment ions indicative of the fatty acid tails present in the lipid, negative ion mode IMS rarely produces PC anions due to ionization suppression from more acidic glycerophospholipids (e.g., phosphatidylethanolamines [PE]). ${ }^{15}$

The extent of structural information that can be obtained during a tandem mass spectrometry experiment is a function of the ion type (e.g., protonated molecule, deprotonated molecule, etc.) and the dissociation method. ${ }^{29}$ On-tissue derivatization and sample doping have 
been used to alter the ion type generated from the tissue surface to alter the structural information obtained upon MS/MS analysis. For example, tissue derivatization via Paternò-Büchi (PB) reactions has been used to identify double bond positions in lipids and tissue doping has been used to generate lithiated ion types to enable lipid acyl chain identification. ${ }^{30-35}$ However, these methods can be time consuming, are irreversible, and can complicate the analysis due to off-target reactions and incomplete reactions. Several alternative ion activation strategies have been recently developed for use during imaging mass spectrometry experiments, including ion/molecule, ion/electron, and ion/photon reactions. For example, ozone-induced dissociation (OzID) ion/molecule reactions have recently been used to identify both $s n$-chain and double bond positions in matrix-assisted laser desorption/ionization (MALDI) imaging experiments. ${ }^{36}$ However, ion/molecule reactions often require reaction times of roughly 10 seconds, making them incompatible with imaging mass spectrometry experiments. Our group has recently demonstrated the use of electron induced dissociation (EID) to structurally characterize lipids from rat brain tissues. ${ }^{37}$ Ultraviolet photodissociation (UVPD) has also been recently used in desorption electrospray ionization (DESI) imaging workflows to identify a variety of lipids. ${ }^{38}$ However, both EID and UVPD require additional hardware (i.e., an electron filament or a laser) and can suffer from poor fragmentation efficiency.

Herein, we demonstrate the ability of ion/ion reactions to alter the ion type in the gas-phase following MALDI ionization in order to provide enhanced chemical structural information for lipids generated directly from tissue surfaces. The McLuckey group and others have previously described a wide variety of ion/ion reactions for use in studying protein conformations, ${ }^{39-44}$ peptide sequences, ${ }^{45-54}$ oligonucleotide sequences,${ }^{55,56}$ and, more recently, lipid structures.${ }^{57-60}$ Gas-phase ion/ion reactions are fast, efficient, and specific, ${ }^{61,62}$ making them ideally suited for use in imaging 
mass spectrometry. We describe here modifications to a commercial hybrid QhFT-ICR MS to enable gas-phase charge inversion ion/ion reactions for the identification of $s n-1$ and $s n-2$ acyl chain positions in mixtures of PC lipids generated directly from rat brain tissue.

\section{EXPERIMENTAL}

\section{Materials}

Acetonitrile, glacial acetic acid, and methanol were purchased from Fisher Chemical (Waltham, MA, USA). Ammonium hydroxide, 1,4-phenylenedipropionic acid, and 1,5diaminonapthalene (DAN) were purchased from Sigma-Aldrich (St. Louis, MO, USA). 1Palmitoyl-2-oleoyl-sn-glycero-3-phosphocholine and 1-oleoyl-2-palmitoyl-sn-glycero-3phospho-choline were purchased from Avanti Polar Lipids, Inc. (Alabaster, AL, USA). Synthetic standard solutions were prepared at $10 \mathrm{mM}$ and mixed $1: 1$ with a $18 \mathrm{mg} / \mathrm{mL}$ solution of DAN MALDI matrix (50/50/0.1 acetonitrile/methanol/acetic acid by volume). One $\mu \mathrm{L}$ aliquots of this mixture were manually spotted onto an MTP AnchorChip MALDI target (Bruker Daltonics, Billerica, MA, USA) and allowed to dry. A 1 mM PDPA reagent solution for ESI was prepared in 49.5/49.5/1 (v/v/v) acetonitrile/methanol/ammonium hydroxide. Rat brain (Brown Norway) was purchased from BioIVT (Westbury, NY, USA) and stored at $-80{ }^{\circ} \mathrm{C}$ until analysis.

\section{Instrumentation}

All experiments were performed on a 7T solariX XR FT-ICR mass spectrometer equipped with an Apollo II dual MALDI/ESI source and a dynamically harmonized ParaCell (Bruker Daltonics, Billerica, MA, USA). The MALDI source employs a Smartbeam II Nd:YAG laser system $(2 \mathrm{kHz}, 355 \mathrm{~nm})$. PC standards were analyzed by performing a manual raster of a MALDI target spot for 2,000 laser shots. Data were collected from $\mathrm{m} / \mathrm{z} 75$ to 2,000 with a mass resolving 
power of $\sim 60,000$ at $m / z \sim 750$ unless otherwise noted and visualized using Compass DataAnalysis 5.0 (Bruker Daltonics, Billerica, MA, USA).

\section{Imaging Mass Spectrometry}

Transverse sections of rat brain were collected at $10 \mu \mathrm{m}$ thickness using a Leica CM 3050S Cryostat (Leica Biosystems, Buffalo Grove, IL, USA) and thaw mounted onto indium tin oxide (ITO)-coated slides. Mounted tissue sections were warmed to room temperature in a desiccator for 30 minutes before application of a DAN MALDI matrix layer using a custom-built sublimation

apparatus $\left(120^{\circ} \mathrm{C}, 8\right.$ minutes, $\left.<70 \mathrm{mTorr}\right) .{ }^{63,64}$ Images were acquired at a pixel spacing of $15 \mu \mathrm{m}$ in both the $\mathrm{x}$ and $\mathrm{y}$ dimensions using a $\sim 10-\mu \mathrm{m}$ laser beam (500 laser shots per pixel). Data were collected from $\mathrm{m} / \mathrm{z} 200$ to 2,000 using a $0.2447 \mathrm{~s}$ time-domain transient length resulting in a mass resolving power of $\sim 18,000$ at $m / z \sim 750$. Internal calibration was performed using known lipid compounds present in the tissue and all mass accuracies are within $1.5 \mathrm{ppm}$. The resulting ion images were visualized using FlexImaging 5.0 (Bruker Daltonics, Billerica, MA, USA) and images are displayed $\pm 0.005 \mathrm{Da}$ without normalization. Following image acquisition, tissue sections were stained using hematoxylin and eosin $(\mathrm{H} \& \mathrm{E})$ and scanned at 10x magnification using a Zeiss Axioscan Z1 brightfield slide scanner (Carl Zeiss Microscopy LLC, White Plains, NY, USA).

\section{Ion/Ion Reactions}

Gas-phase charge inversion ion/ion reactions were performed on the solariX FT-ICR MS using the existing commercial hardware. ${ }^{65}$ This instrument is capable of performing electron transfer dissociation (ETD) ion/ion reactions between multiply charged cation analytes generated via ESI and singly charged fluoranthene radical anions generated from a chemical ionization 
source located after the ion funnel interface region (Figure 1). The ETD capabilities are described here first as they have been modified to accommodate the charge inversion ion/ion reactions used in this work. The intent is not to provide an exhaustive description of ETD, but rather to enable understanding of the charge inversion reaction within the context of the existing ETD instrument framework. In the ETD experiment, the cations are first injected through the quadrupole mass filter and stored in the instrument collision cell, a hexapole ion trap, using DC potentials. A supplemental AC trapping potential, termed the Mirror RF, is then quickly (in less than $1 \mathrm{~ms}$ ) applied to the collision cell rods and the trapping DC potentials removed. ${ }^{65}$ The ion polarity of the front end of the instrument is then switched to transmit negative reagent ions from the CI source to the collision cell. This includes applying a large negative potential to Skimmer 2 that causes any positive ions produced from the ESI source to be lost on Skimmer 2. The Mirror RF allows for the mutual storage of the positive and negative ion populations in the hexapole ion trap. After a defined reaction period, DC trapping potentials are again applied to the hexapole ion trap and the Mirror RF removed. ${ }^{65}$ Any residual reagent anions are no longer confined within the collision cell. At this stage, some of the precursor analyte cations have been charged reduced via the electron transfer reaction with the fluoranthene radical anions. The residual precursor and resulting product ions are both positively charged and remain confined within the hexapole ion trap. At this point, a second round of ESI cations can be injected into the collision cell for lock mass purposes. DC potentials are then applied to the collision cell to extract the ions and transfer them to the ICR cell. This demonstrates the capability of the existing instrument hardware to accommodate mutual storage of ions of opposing polarities within the hexapole ion trap and the ability of the front end of the instrument to rapidly switch the voltage polarities of the ion optical elements. 
Charge inversion ion/ion reactions have been enabled via software modifications to the ETD pulse program. The ion/ion reaction employed in this work involves the reaction of singly charged analyte cations produced via MALDI with doubly charged reagent anions produced via ESI to produce a singly charged, charge inverted analyte anion:

$$
[\mathrm{A}+\mathrm{H}]^{+}+[\mathrm{R}-2 \mathrm{H}]^{2-} \rightarrow[\mathrm{A}+\mathrm{R}-\mathrm{H}]^{-}
$$

In order to allow negative ion mode ESI in the same experimental scan as positive ion mode MALDI, parameter relation scripts controlling the source optics were modified to allow voltage values opposite to the system polarity only during the ETD event timeslice. The reaction follows a similar sequence to that mentioned above for the ETD reaction, except the MALDI source is now used instead of the CI source and ion detection is performed in the same polarity as the MALDI event rather than the ESI event. The "Reagent Tune Mode" of the ETD functionality has been altered to allow for negative ion mode ESI, positive ion mode MALDI, and negative ion mode detection. This includes variable voltage control of the Funnel 2, Skimmer 2, DC Bias (Reagent Source Transfer), hexapole entrance lens, hexapole exit lens, and collision cell bias at different times during the pulse program. The current experiment now allows for the sequential injection of ESI-generated anions followed by MALDI-generated anions into the hexapole collision cell (Figure 1a). Both ion populations can be sequentially isolated during transmission through the quadrupole mass filter prior to mutual storage in the collision cell (Figure 1b). Briefly, the Mirror $\mathrm{RF}$ is removed following a defined ion/ion reaction period and any residual analyte cations are no longer confined within the collision cell. At this stage, some of the precursor analyte cations have been charged inverted via reaction with the reagent dianions. Residual precursor reagent and 
resulting product complex ions are both positively charged and remain confined within the hexapole ion trap. This ion population is transferred to the ICR cell where mass isolation, sustained off-resonance collision induced dissociation (SORI CID), and mass analysis are performed. The anion accumulation $(50 \mathrm{~ms})$, cation accumulation $(500 \mathrm{~ms})$, and mutual storage reaction time (1.5 s) used here resulted in a total experimental reaction time of 2.05 seconds (Figure 1a). SORI was performed with argon collision gas using an optimized power setting (this varied from $1.8 \%$ to $2.2 \%), 5 \mathrm{~ms}$ pulse length, and $550 \mathrm{~Hz}$ frequency offset. External mass calibration was not possible due to DataAnalysis software limitations caused by the instrument polarity switching. As such, mass accuracies of all product and fragment ions are within $15 \mathrm{ppm}$ (i.e., instead of the $1.5 \mathrm{ppm}$ limit mentioned above for IMS experiments).

a)
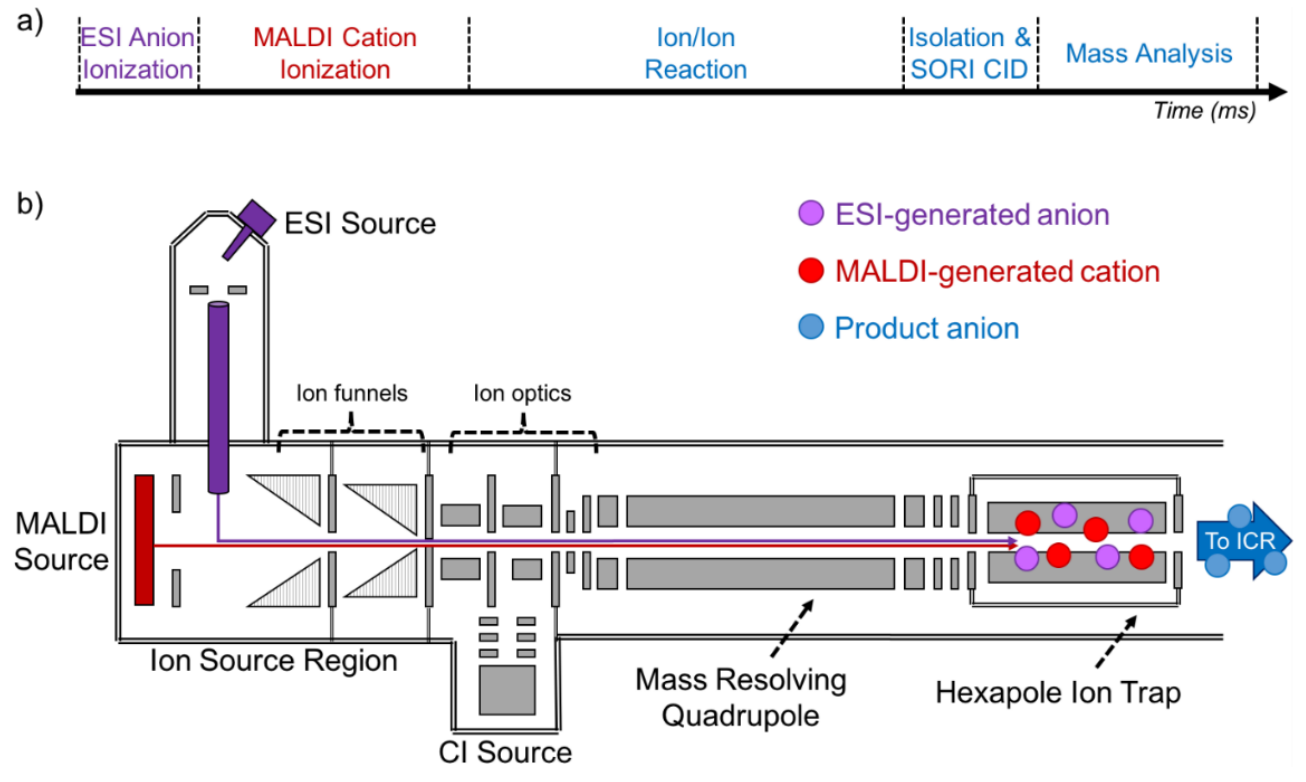

Figure 1. a) Instrument timing diagram showing reagent and analyte ion injection (50 ms and 500 $\mathrm{ms}$, respectively), ion/ion reaction (1.5 s), product ion isolation and SORI CID ( 10 ms), and mass analysis $(\sim 0.75 \mathrm{~s})$ in the ICR cell. The entire ionization and reaction process takes $\sim 2-3$ seconds. b) A simplified instrument diagram depicts the ion/ion reaction operation on the solariX instrument platform. This chemistry is enabled by sequentially injecting ESI-generated anions followed by MALDI-generated cations through a mass resolving quadrupole into a hexapole ion trap. Following a defined mutual storage reaction period, the product ions are transferred to the ICR for isolation, SORI CID, and mass analysis. The transfer optics from the hexapole ion trap to the ICR cell and the ICR electrodes have been omitted from the instrument diagram for simplicity. Note that the timing and instrument diagrams are not drawn to scale. 


\section{RESULTS AND DICUSSION}

\section{Charge Inversion Ion/Ion Reaction Chemistry}

Collision induced dissociation of protonated PC cations typically results in production of a phosphocholine product ion of $\mathrm{m} / \mathrm{z} 184.073$ (Figure S1) ${ }^{28}$ This fragment ion is diagnostic for the PC lipid class, but does not provide any information about the identity or relative position of the lipid fatty acyl groups. While CID of deprotonated PCs produces fragment ions specific to the lipid fatty acyl groups, $\mathrm{PC}$ anions are not readily generated from the tissue surface due to ionization suppression. A gas-phase charge inversion step after ion generation but prior to mass analysis would thus be ideally suited to PC acyl chain identification in MALDI IMS. Di-acid anions have been previously shown to coordinate with gaseous cations during ion/ion reactions, resulting in the formation of the desired anionic complex. ${ }^{66}$ Specifically, the McLuckey group has demonstrated that a 1,4-phenylenedipropionic acid (PDPA) di-acid can form a long-lived anionic complex with PCs. ${ }^{57,58} \mathrm{CID}$ of this complex causes PDPA to abstract a proton and a methyl group from the fixed charge choline lipid head group to produce a demethylated PC anion (Scheme 1):

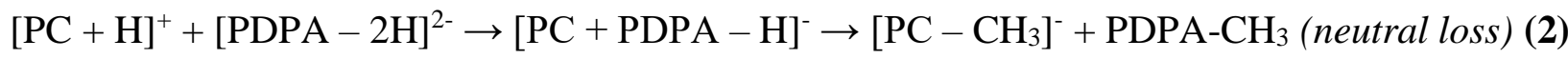

Spontaneous dissociation of the complex (i.e., without supplemental ion activation) to yield the demethylated PC anion may also be observed. This loss is likely driven by the energy available from the Coulombic recombination of the cation and anion, which can help drive a gas-phase reaction over some energetic barriers. ${ }^{67}$ 


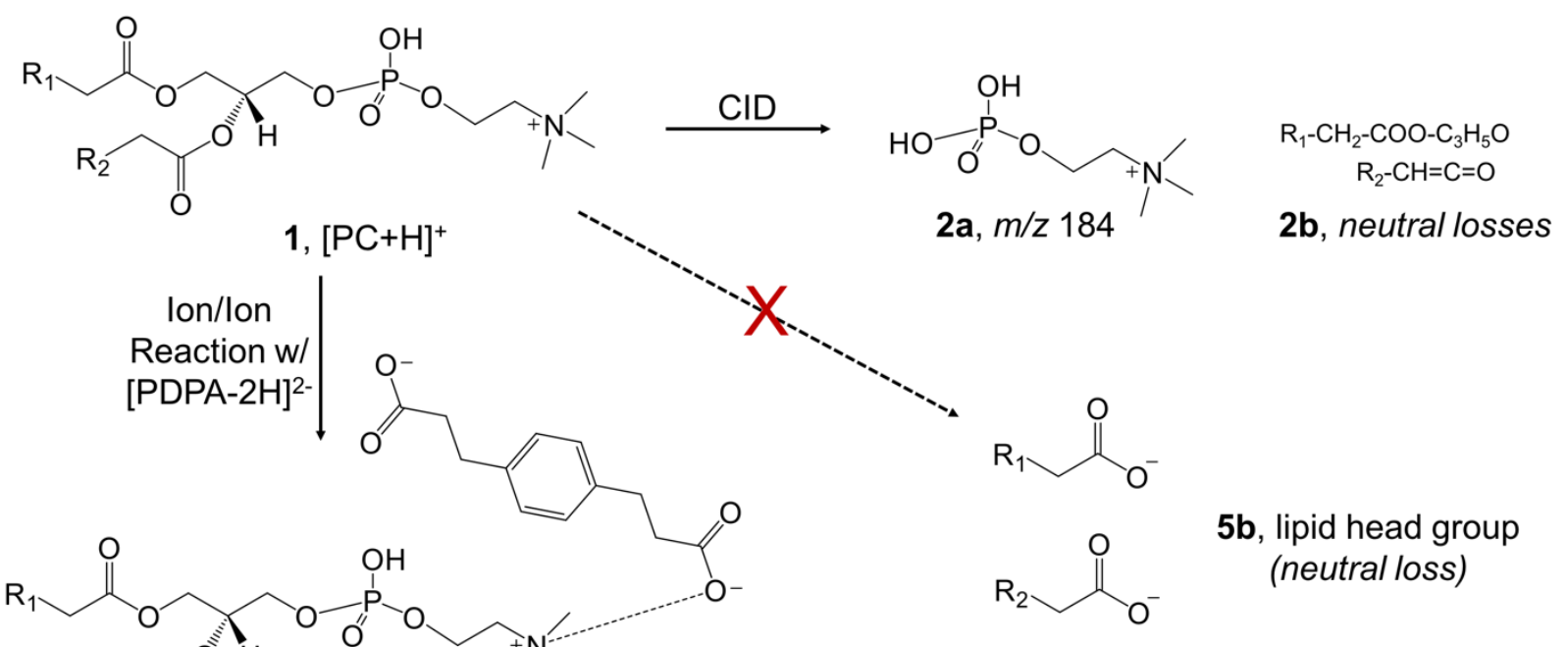

$\mathbf{5 a}$, deprotonated

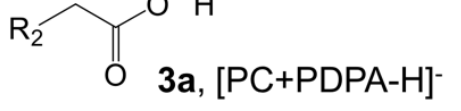
fatty acid tails

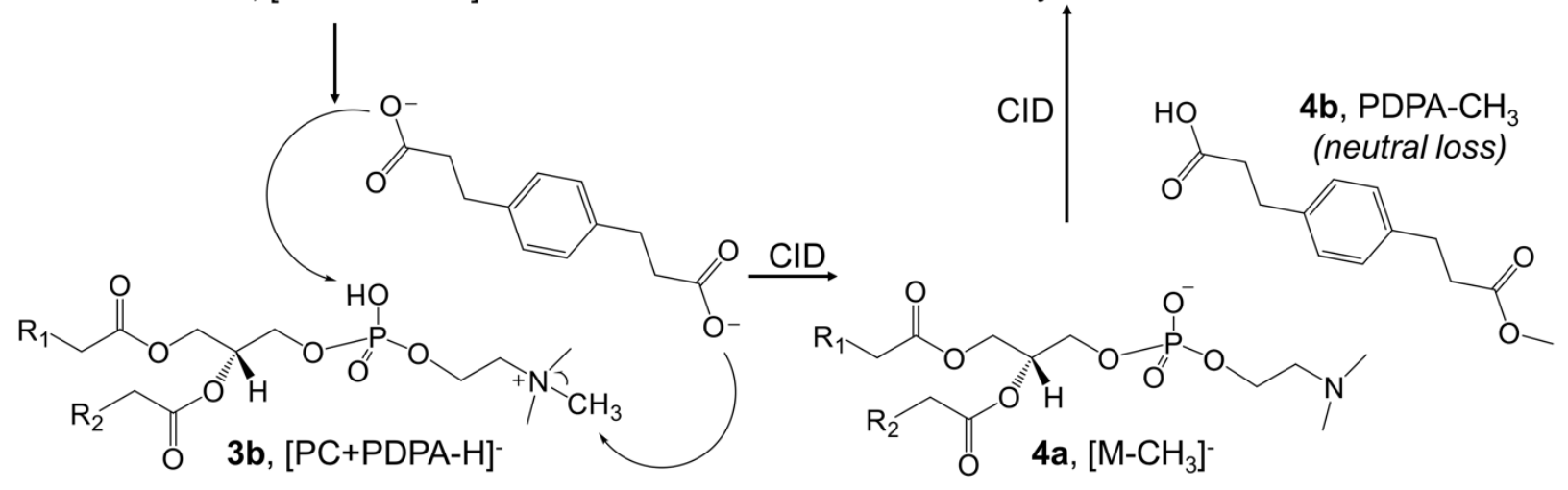

Scheme 1. Gas-phase charge inversion ion/ion reaction between a singly charged PC cation (1) and a doubly deprotonated 1,4-phenylenedipropionic acid (PDPA) reagent anion results in a longlived reaction complex (3a and 3b). Activation of this complex produces a demethylated PC product anion (4a). Subsequent CID of the anion produces fragments indicative of the fatty acid tails (5a). CID of the protonated PC precursor ion mainly results in production of a phosphocholine ion $(\mathbf{2 a})$.

We have demonstrated a proof-of-principle charge inversion ion/ion reaction on our system using a $\mathrm{PC}_{34: 1}$ lipid standard and PDPA. This reaction produces a charge inverted $\left[\mathrm{PC}_{34: 1}+\mathrm{PDPA}\right.$ $-\mathrm{H}]^{-}$complex ion and a demethylated PC ion (Figure $\mathbf{2 b}$ and $\mathbf{2 c}$ ). Proton transfer from the PC to PDPA to produce a charge reduced $[\mathrm{PDPA}-\mathrm{H}]^{-}$ion represents a competing reaction channel and is also observed (Figure 2c). SORI CID of the PC/PDPA complex results in exclusive primary production of the demethylated PC anion, though fatty acyl cleavages are also observed as a result 
of consecutive fragmentation from the $\left[\mathrm{PC}-\mathrm{CH}_{3}\right]^{-}$ion (data not shown). Isolation and SORI CID of the demethylated PC ion provides fragmentation diagnostic for the fatty acid tail identity and position (Figure 2d). The identities of the two fatty acyl groups are easily determined to be 16:0 and 18:1 based on the respective masses of the two major fragment ions. The sn-positions of these two groups can be inferred by examining the relative intensities of the fragment ions. Under low energy CID conditions, cleavage at the lipid $s n-2$ position is favored (i.e., the intensity of the 18:1 fragment ion is roughly twice that of the 16:0 fragment ion). ${ }^{28}$ Based on the results of Figure 2d, the identity of the lipid standard is confirmed to be $\mathrm{PC}_{16: 0 / 18: 1}$.
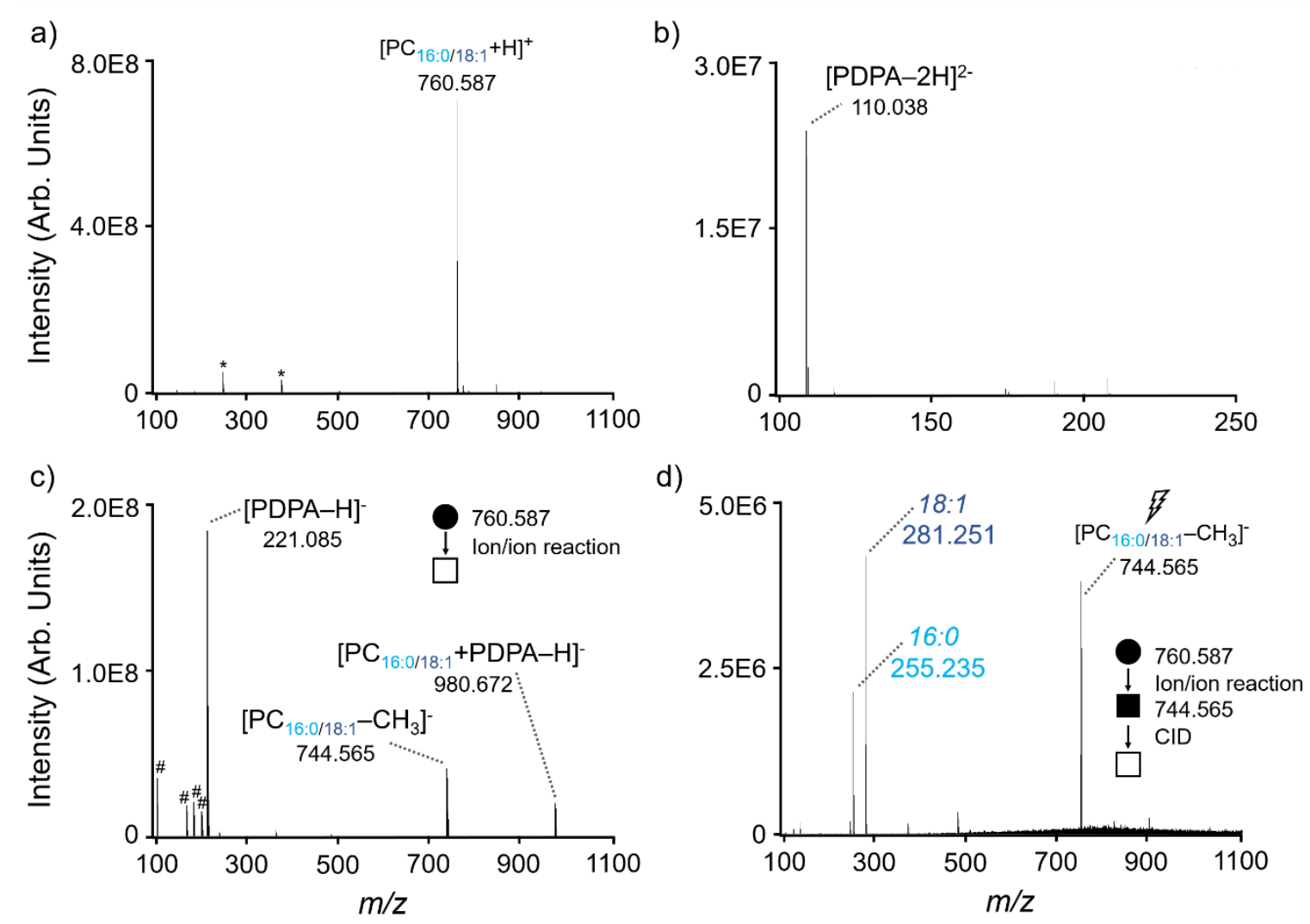

Figure 2. A charge inversion ion/ion reaction between a) $\mathrm{PC}_{16: 0 / 18: 1}$ and b) [PDPA-2H] ${ }^{2-}$ dianions c) produces a PC/PDPA anionic complex and a demethylated PC anion. d) Ion isolation of the demethylated PC anion followed by SORI CID produces fragment ions diagnostic for the 16:0 and 18:1 fatty acid tails in the lipid, allowing for the identification as $\mathrm{PC}_{16: 0 / 18: 1}$. Note that circles $(\bullet /$ $\circ)$ indicate positive ion mode analysis, squares $(\square / \mathbf{\square})$ indicate negative ion mode analysis, \# denotes fragment ions related to PDPA, * denotes harmonics/electronic noise, and the lightning bolt is used to denote the ion subjected to CID. All spectra are single scan measurements. 
The ability of the charge inversion workflow to distinguish between sn-positional isomers was confirmed by comparing the behavior of $\mathrm{PC}_{16: 0 / 18: 1}$ and $\mathrm{PC}_{18: 1 / 16: 0}$ lipid standards. As with $\mathrm{PC}_{16: 0 / 18: 1}, \mathrm{PC}_{18: 1 / 16: 0}$ also readily produces a PC/PDPA complex and a demethylated PC anion (Figure 3b). SORI CID of the $\left[\mathrm{PC}-\mathrm{CH}_{3}\right]^{-}$ion again produces fragment ions indicative of 16:0 and 18:1 fatty acids (Figure 3c). However, the intensity of the 16:0 fragment ion is now roughly twice that of the 18:1 fragment ion. This allows for the localization of the 18:1 and 16:0 fatty acids to the $s n-1$ and $s n-2$ positions of the lipid, respectively. The intensity ratio of $16: 0$ to $18: 1$ for $\mathrm{PC}_{18: 1 / 16: 0}$ in Figure 3c is inverted compared to that of $\mathrm{PC}_{16: 0 / 18: 1}$ in Figure 2d. It should also be noted that cleavages at the ketene positions are also observed in low abundance in Figures $2 \mathbf{d}$ and 3c, but has been excluded from this discussion for simplicity. 
a)

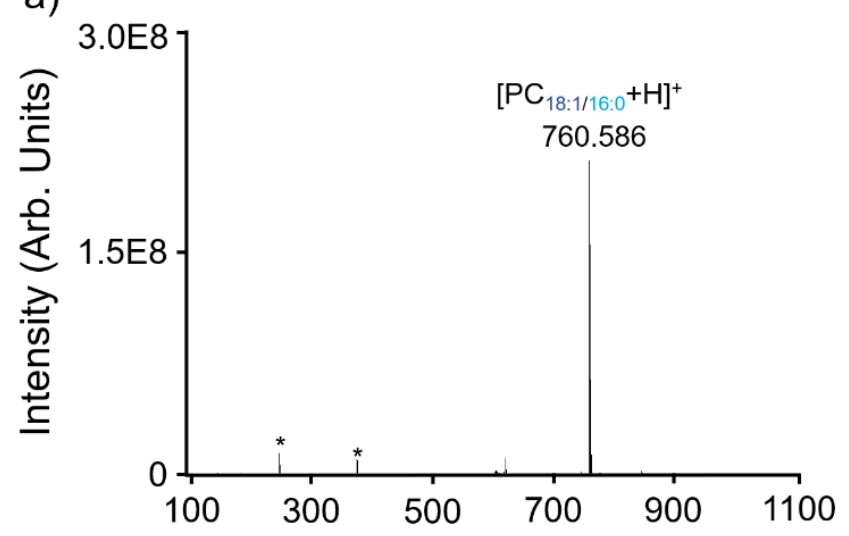

b)
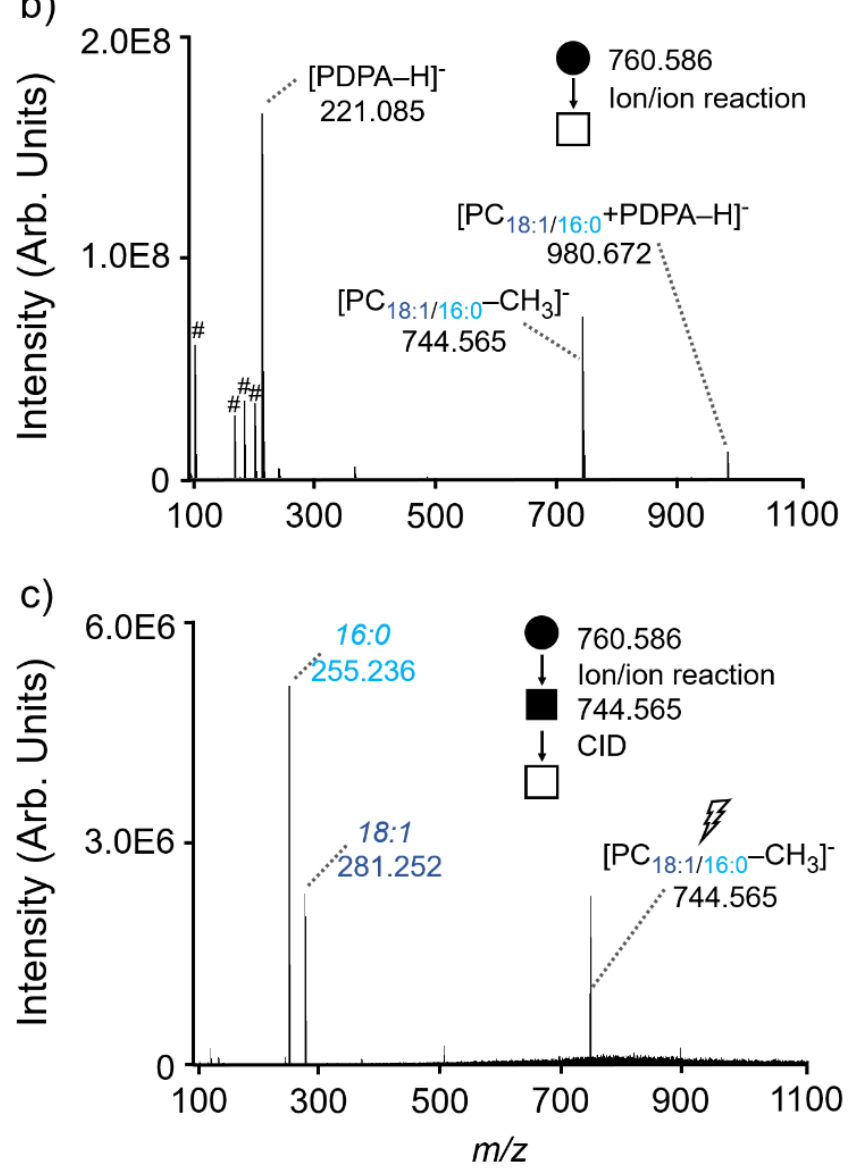

Figure 3. A PDPA charge inversion ion/ion reaction of a) $\mathrm{PC}_{18: 1 / 16: 0}$ b) produces a PC/PDPA anionic complex and a demethylated PC anion. c) Ion isolation of the demethylated PC anion followed by SORI CID produces fragment ions diagnostic for the 18:1 and 16:0 fatty acid tails in the lipid, allowing for the identification as $\mathrm{PC}_{18: 1 / 16: 0}$. Note that circles $(\bullet / 0)$ indicate positive ion mode analysis, squares $(\square / \mathbf{0})$ indicate negative ion mode analysis, \# denotes fragment ions related to PDPA, * denotes harmonics/electronic noise, and the lightning bolt is used to denote the ion subjected to CID. All spectra are single scan measurements. 


\section{Lipid Identification in Tissue Samples}

The charge inversion ion/ion reaction workflow has been extended to the identification of PCs in tissue. Positive ion mode imaging mass spectrometry analysis of rat brain enables the detection of a wide range of PCs. The ion signal at $\mathrm{m} / \mathrm{z} 760.585$ is tentatively identified as $\mathrm{PC}_{34: 1}$ based on a high resolution accurate mass measurement (Figure 4a). This ion is isolated using the quadrupole mass filter (Figure $\mathbf{4 b}$ ) and subjected to an ion/ion reaction with doubly deprotonated PDPA, resulting in the formation of $\left[\mathrm{PC}_{34: 1}+\mathrm{PDPA}-\mathrm{H}\right]^{-}$and $\left[\mathrm{PC}_{34: 1}-\mathrm{CH}_{3}\right]^{-}$product ions (Figure 4c). SORI CID of the demethylated product ion results in acyl chain fragmentation, revealing the presence of 16:0 and 18:1 chains (Figure 4d). 
a)

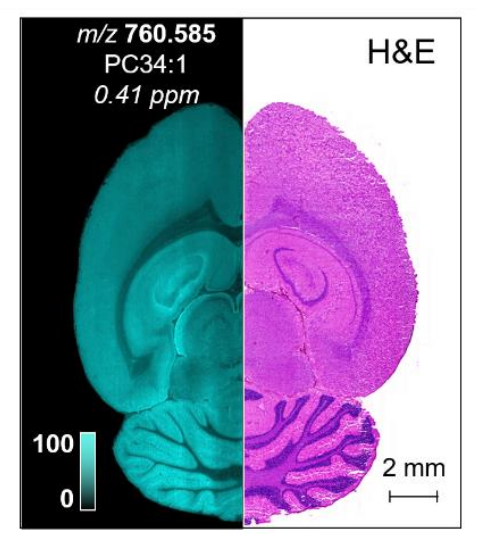

c)

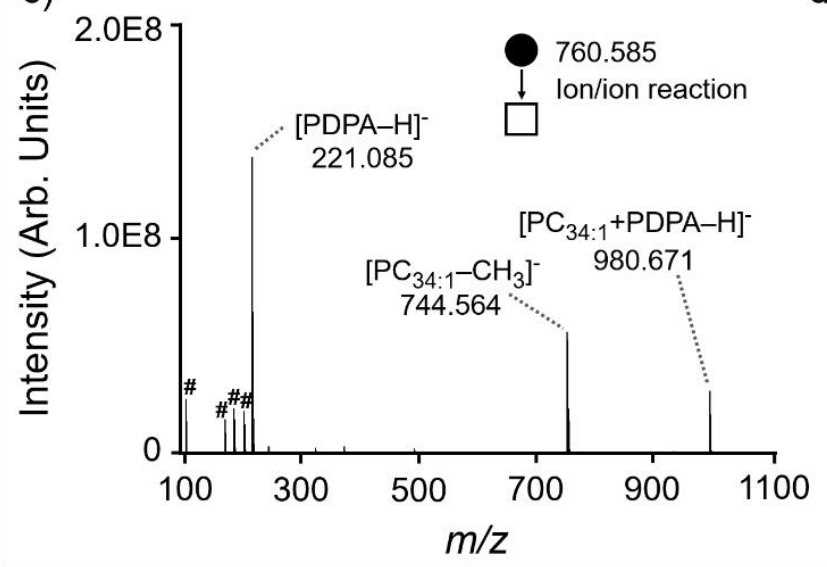

b)

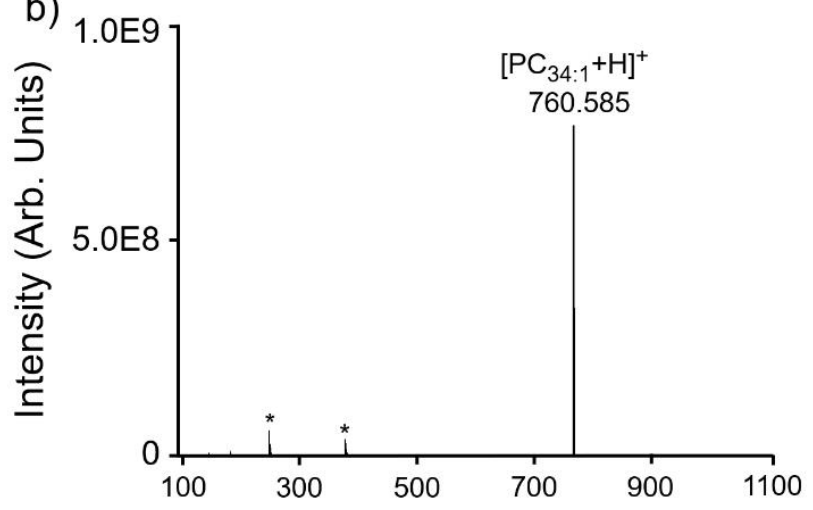

d)

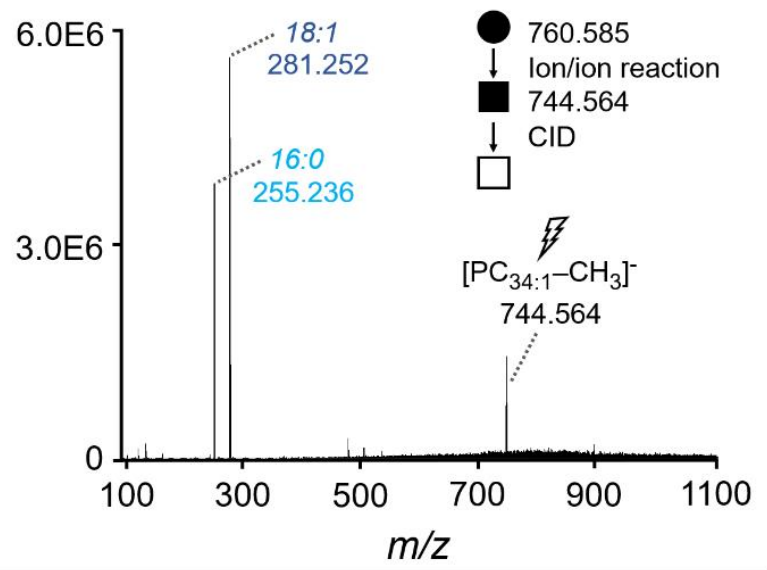

Figure 4. a) Ion image for $m / z 760.585$ in rat brain, tentatively identified as $\mathrm{PC}_{34: 1}$ by an accurate mass measurement. A PDPA charge inversion ion/ion reaction of b) $\mathrm{PC}_{34: 1}$ generated directly from the tissue surface c) produces a PC/PDPA anionic complex and a demethylated PC anion. d) Ion isolation of the demethylated PC anion followed by SORI CID produces fragment ions diagnostic for the 16:0 and 18:1 fatty acid tails in the lipid, allowing for the identification as PC 16:0_18:1. Note that circles $(\bullet / \circ)$ indicate positive ion mode analysis, squares $(\square / \boldsymbol{\square})$ indicate negative ion mode analysis, \# denotes fragment ions related to PDPA, * denotes harmonics/electronic noise, and the lightning bolt is used to denote the ion subjected to CID. All spectra are single scan measurements.

At first glance, the relative intensities of the 16:0 and 18:1 acyl chain fragment ions shown in Figure 4d suggest the identity of $\mathrm{PC}_{34: 1}$ to be $\mathrm{PC}_{16: 0 / 18: 1}$. However, $\mathrm{PCs}$ measured in biological tissue samples are likely a mixture of $s n$-positional isomers. As such, $\mathrm{PC}_{34: 1}$ is likely a mixture of both $\mathrm{PC}_{16: 0 / 18: 1}$ and $\mathrm{PC}_{18: 1 / 16: 0}$ isomers. In order to determine the relative contribution of each isomer, a calibration curve measuring the relative 16:0 and 18:1 fragment ion intensities is 
constructed using defined mixtures of lipid standards. Briefly, manually-spotted mixtures of $\mathrm{PC}_{16: 0 / 18: 1}$ and $\mathrm{PC}_{18: 1 / 16: 0}$ standards containing varying fractional amounts of each isomer were prepared on an MTP AnchorChip MALDI target and then subjected to the ion/ion charge inversion reaction workflow (Figure S2). The intensity of the 18:1 fragment ion to the summed intensities of the 16:0 and 18:1 fragment ions is found to have a linear relationship with lipid isomer content (Figure 5a). By this, the relative fractional contribution of each $\mathrm{PC}_{16: 0 \_18: 1}$ isomer in tissue can be determined via comparison to the standard curve. This methodology has been used to examine the relative isomer contribution of $\mathrm{PC}_{16: 0 \_18: 1}$ in different regions of rat brain tissue (Figure 5b). Six different structures in the brain were measured ( $\mathrm{n}=10$ for each), including the granular layer, molecular layer, cerebral cortex, hippocampus, white matter, and corpus callosum (Figure 5c). The relative fraction of $\mathrm{PC}_{16: 0 / 18: 1}$ and $\mathrm{PC}_{18: 1 / 16: 0}$ isomers was determined to vary by over $25 \%$ throughout multiple brain substructures. Specifically, the relative fraction of $\mathrm{PC}_{16: 0 / 18: 1}$ was found to be $50.1 \% \pm 1.9 \%$ in the granular layer, $58.7 \% \pm 2.5 \%$ in the molecular layer, $65.2 \% \pm 3.6 \%$ in the cerebral cortex, $71.7 \% \pm 4.0 \%$ in the hippocampus, $76.1 \% \pm 3.1 \%$ in the white matter, and $76.5 \% \pm 2.1 \%$ in the corpus callosum. These differences are likely due to differences in lipid biosynthesis and may be important for proper functionality of cells in different regions of the brain. ${ }^{68}$ Without the isomeric information provided by this novel tandem mass spectrometry method, these differences would not be resolved. 


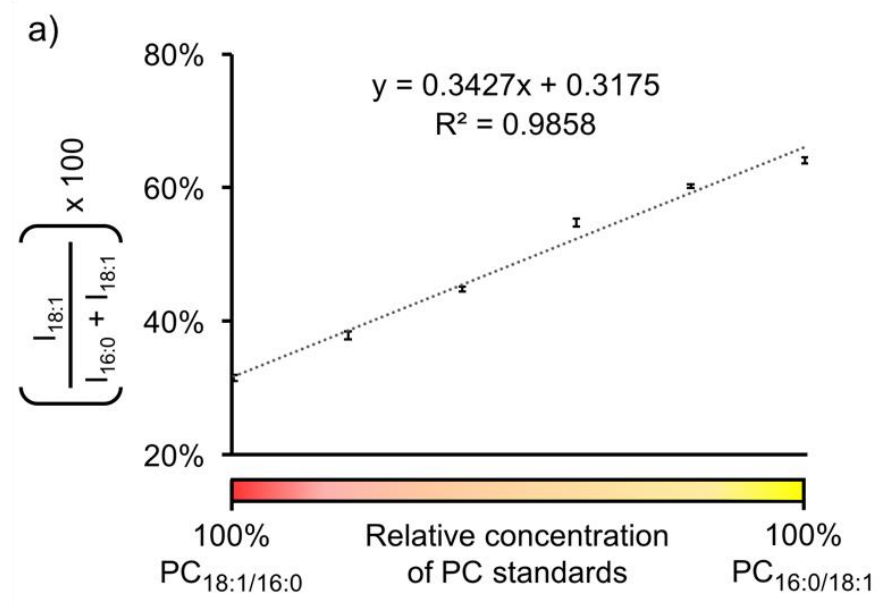

b)
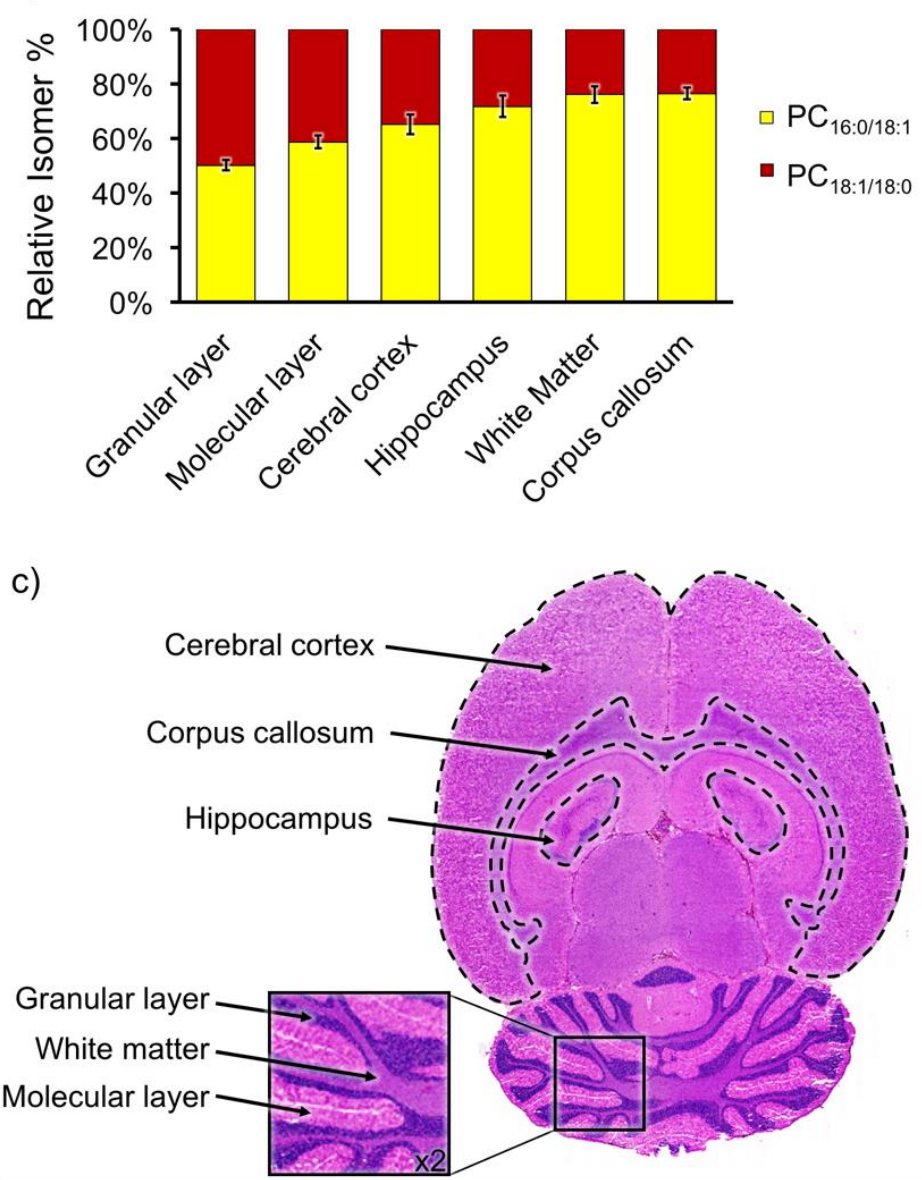

Figure 5. a) Mixtures of $\mathrm{PC}_{16: 0 / 18: 1}$ and $\mathrm{PC}_{18: 1 / 16: 0}$ lipid standards are used to calibrate the 18:1/(18:1+16:0) fragment ion intensity ratio obtained via $\mathrm{CID}$ of the $\left[\mathrm{PC}_{34: 1}-\mathrm{CH}_{3}\right]^{-}$anion produced via the PC/PDPA charge inversion reaction. b) The ion/ion reaction method reveals that the relative isomeric content of $\mathrm{PC}_{34: 1}$ varies throughout rat brain. Each measurement in the standard curve and each region of the brain is the average of 10 spectra. c) H\&E stained tissue showing regions of interest. 
Extending this PC/PDPA charge inversion scheme to other phosphatidylcholine ions reveals that many lipids detected from rat brain tissue are mixtures of multiple isomer pairs. For example, $\mathrm{PC}_{36: 1}$ is comprised of $\mathrm{PC}_{18: 0 \_18: 1}$ and $\mathrm{PC}_{20: 1 \_16: 0}$, which are readily distinguished using the charge inversion reaction (Figure 6). $\mathrm{PC}_{36: 1}$ then consists of four $s n$-positional isomers: $\mathrm{PC}_{18: 0 / 18: 1}, \mathrm{PC}_{18: 1 / 18: 0}, \mathrm{PC}_{20: 1 / 16: 0}$, and $\mathrm{PC}_{16: 0 / 20: 1 .}$. Determination of the relative contributions of these four isomers to the overall $\mathrm{PC}_{36: 1}$ ion signal would require generation of calibration curves similar those used with $\mathrm{PC}_{34: 1}$, which is dependent on the availability, affordability, and purity ${ }^{69}$ of synthetic lipid standards. Nonetheless, the identification of multiple isomers represents an improvement over the sum-composition identification of $\mathrm{PC}_{34: 1}$. Using the charge inversion scheme to analyze $\mathrm{PC}_{36: 2}$ reveals a mixture of five positional isomers: $\mathrm{PC}_{16: 0 / 20: 2}, \mathrm{PC}_{20: 2 / 16: 0}$,

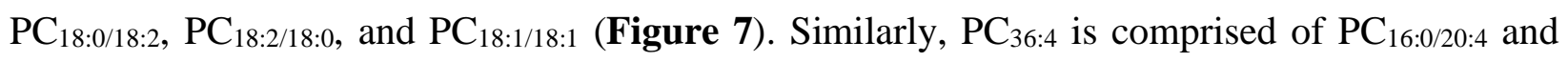
$\mathrm{PC}_{20: 4 / 16: 0}$ (Figure S3) and $\mathrm{PC}_{38: 6}$ is comprised of $\mathrm{PC}_{\text {16:0/22:6 }}$ and $\mathrm{PC}_{22: 6 / 16: 0}$ (Figure S4). It should be noted that $\mathrm{CO}_{2}$ loss from the 20:4 and 22:6 fatty acyl groups is also observed here. This dissociation behavior has been previously reported for long chain fatty acids. ${ }^{70}$ 
a)
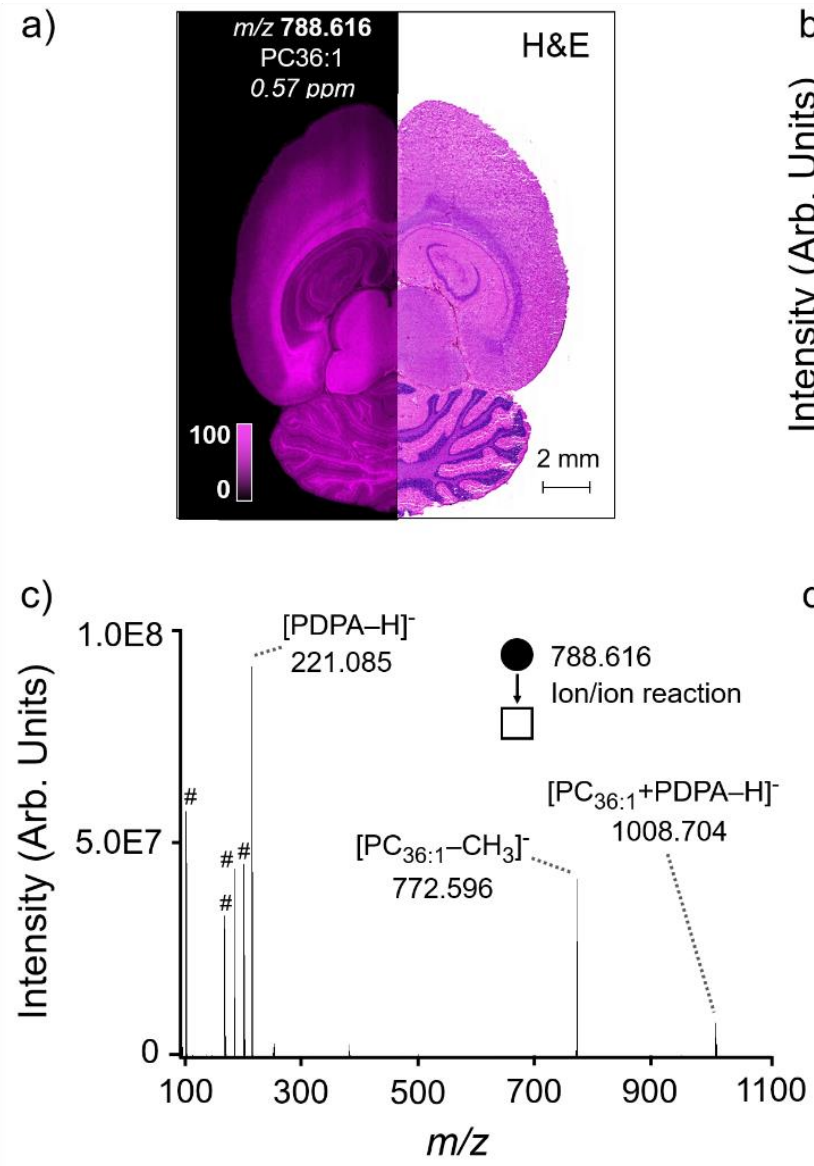

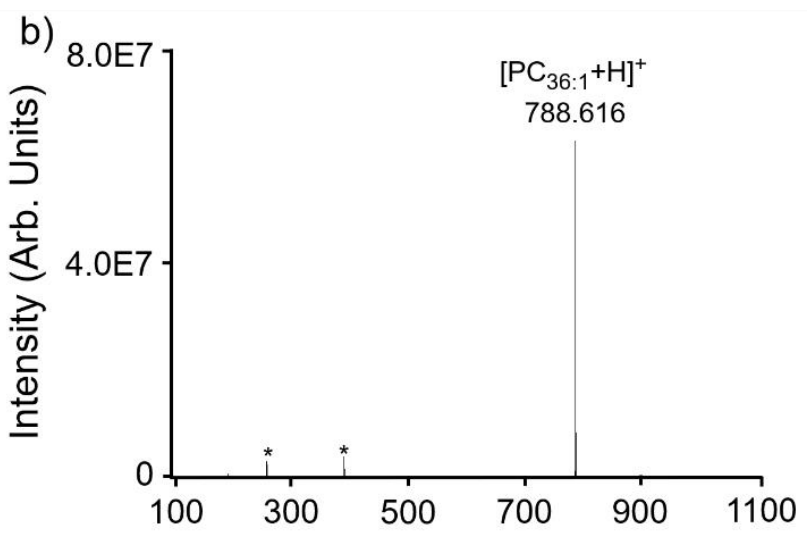

d)

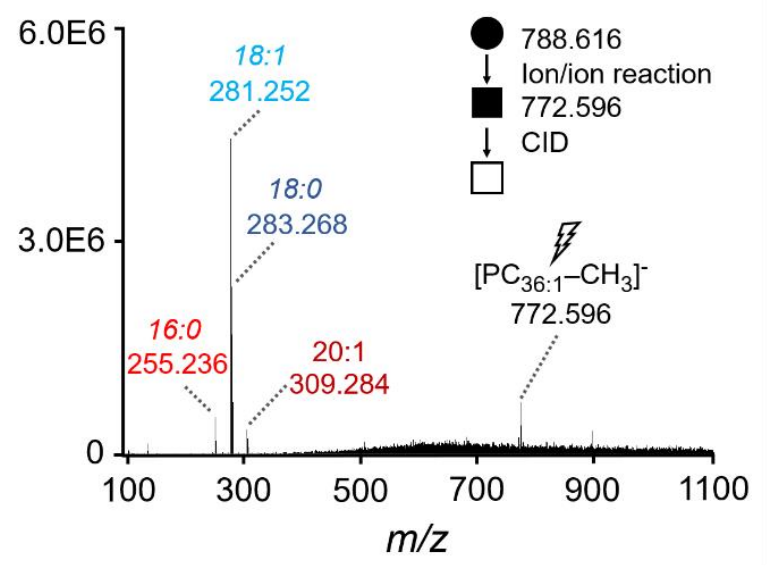

Figure 6. a) Ion image for $m / z 788.616$ in rat brain, tentatively identified as $\mathrm{PC}_{36: 1}$ by an accurate mass measurement. A PDPA charge inversion ion/ion reaction of $b$ ) $\mathrm{PC}_{36: 1}$ generated directly from the tissue surface c) produces a PC/PDPA anionic complex and a demethylated PC anion. d) Ion isolation of the demethylated PC anion followed by SORI CID produces fragment ions diagnostic for 16:0, 18:1, 18:0, and 20:1 fatty acid tails in the lipid, allowing for the identification of $\mathrm{PC}_{18: 0 \_18: 1}$ and $\mathrm{PC}_{20: 1 \_16: 0}$ isomers. Note that circles $(\bullet / \circ)$ indicate positive ion mode analysis, squares $(\square /$ ש) indicate negative ion mode analysis, \# denotes fragment ions related to PDPA, * denotes harmonics/electronic noise, and the lightning bolt is used to denote the ion subjected to CID. All spectra are single scan measurements. 
a)
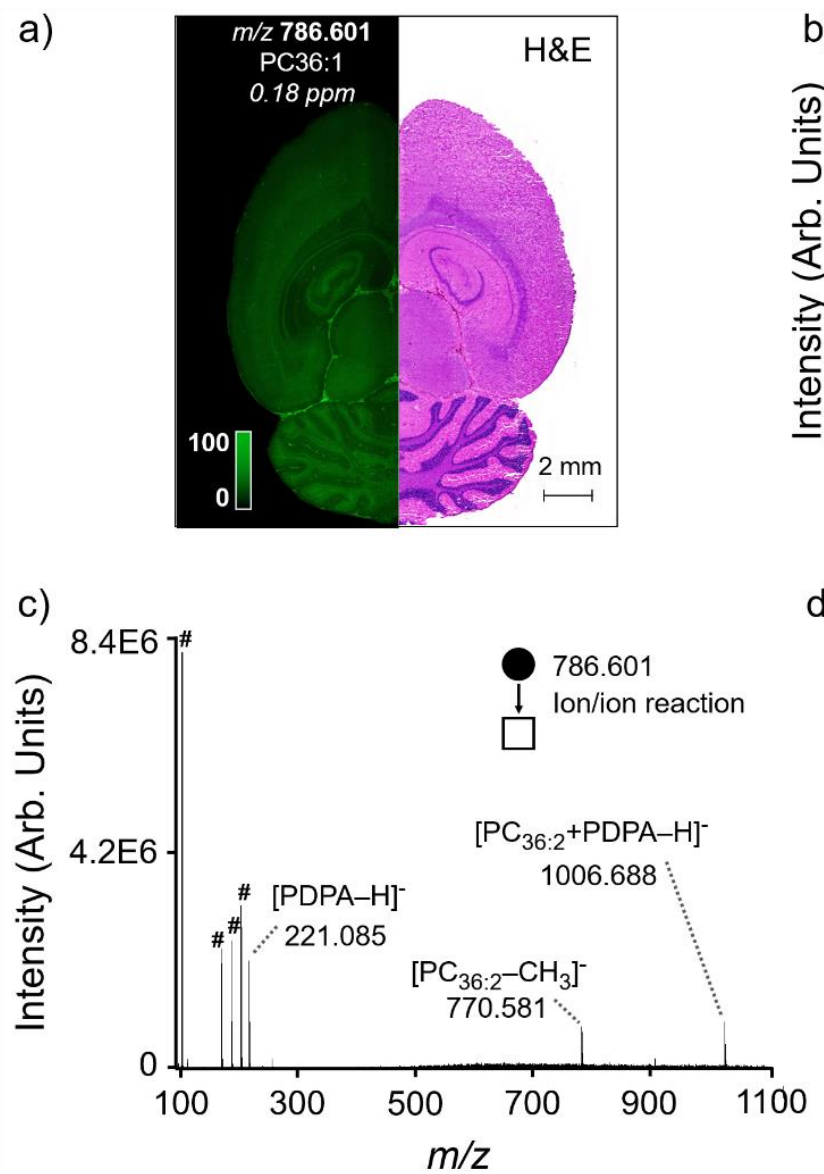

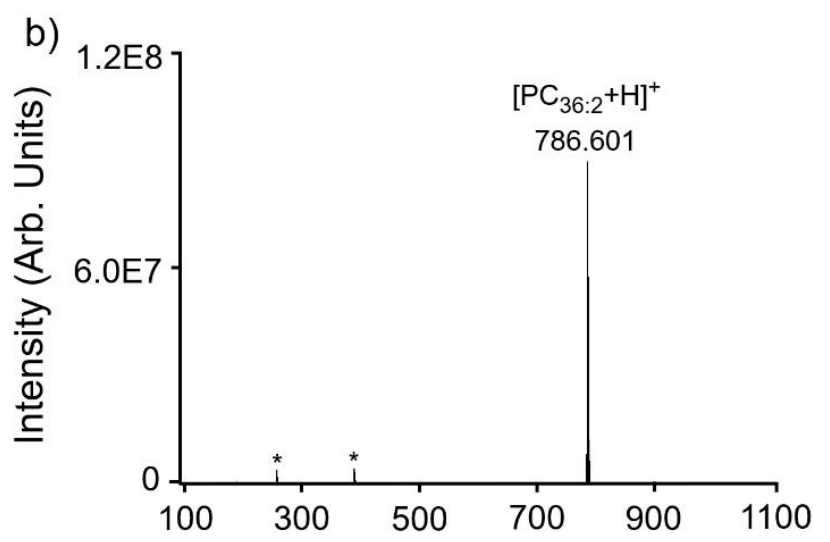

d)

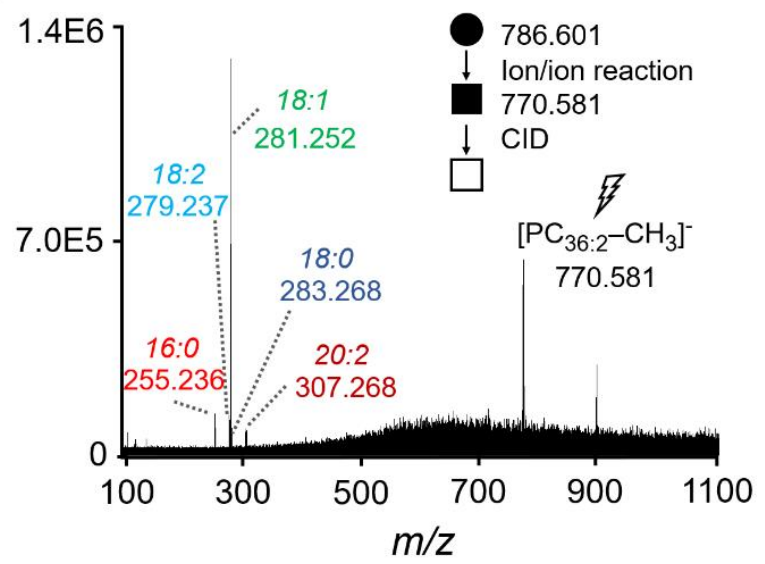

Figure 7. a) Ion image for $m / z 786.601$ in rat brain, tentatively identified as $\mathrm{PC}_{36: 2}$ by an accurate mass measurement. A PDPA charge inversion ion/ion reaction of b) $\mathrm{PC}_{36: 2}$ generated directly from the tissue surface c) produces a PC/PDPA anionic complex and a demethylated PC anion. d) Ion isolation of the demethylated PC anion followed by SORI CID produces fragment ions diagnostic for 16:0, 18:2, 18:1, 18;0, and 20:2 fatty acid tails in the lipid, allowing for the identification of

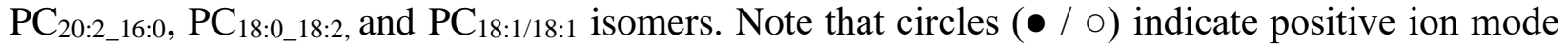
analysis, squares ( $\square / \mathbf{\square})$ indicate negative ion mode analysis, \# denotes fragment ions related to PDPA, * denotes harmonics/electronic noise, and the lightning bolt is used to denote the ion subjected to CID. All spectra are single scan measurements.

Given that the mass spectrometry signal for each lipid ion is actually arising from multiple different isomeric compounds, and given that the relative contribution of these isomers varies in different regions of the tissue, it is clearly insufficient to map the distribution of these lipids using only their mass-to-charge ratio. Imaging mass spectrometry analysis of, for example $\mathrm{PC}_{36: 2}$ will give an incomplete story of lipid abundance. Additional isomers likely exist when considering the 
positions and orientations of the double bonds in the fatty acid tails (e.g., 6Z or 9Z) and are beyond the scope of the current report. In general, the identification results shown here are in agreement with measurements made with other alternative gas-phase approaches, such as OzID ${ }^{36}$ and EID. ${ }^{37}$ However, ion/molecule reactions like OzID are inherently slower than ion/ion reactions (e.g., a modestly sized 10,000 pixel image would require almost 28 hours to complete using a 10 -second ion/molecule reaction period). Ion/electron reactions such as EID are inefficient and require averages of 50 to 100 spectra to attain sufficient signal-to-noise ratios for analyte identification. By comparison, the PC/PDPA ion/ion reaction used here requires a two-second reaction period, which can likely be shortened. Currently, SORI, which introduces a pulse of argon gas to the ICR cell, is used to perform subsequent CID on the reaction product. In order to maintain high vacuum, the pressure in the ICR cell must return to a baseline reading before a second SORI experiment can be performed, which can take up to one minute. This prevents the usage of multiple stages of SORI CID (e.g., to dissociate the PC/PDPA complex and then to subsequently dissociate the demethylated product ion) and is not compatible with imaging experiments that require the sequential acquisition of thousands of pixels. Current work is underway to further improve the reaction efficiency and to enable ion dissociation more compatible with imaging mass spectrometry.

\section{CONCLUSIONS}

Despite the high level of molecular specificity afforded by imaging mass spectrometry, the chemical complexity of tissue samples presents unique challenges in resolving and identifying compounds of interest. The failure to adequately separate and identify these compounds results in ion images that represent the confluence of several compounds that have overlapping $\mathrm{m} / \mathrm{z}$ values, 
resulting in inaccurate depictions of molecular distributions. Accurate analyte identification is critical for identifying the roles these molecules play in various cellular functions and for determining the biochemical pathways that are altered under pathophysiological conditions. We have demonstrated here the use of gas-phase charge inversion ion/ion reactions using a PDPA reagent to identify PC sn-positional isomers in rat brain tissue. Given these results, most PCs in biological tissues are likely mixtures of at least two sn-positional isomers (e.g., $\mathrm{PC}_{36: 2}$ in rat brain was found to contain five positional isomers), and the relative contributions of these isomers likely varies in different regions of the tissue. The gas-phase approach employed here is rapid, is easily and precisely computer-controlled, and does not physically or chemically alter the original tissue sample. Due to the widespread adoption of ETD, the instrument hardware required to perform ion/ion reactions is increasingly available on a variety of MS platforms. The ability to alter the ion type from the initial form generated during ionization to a more structurally informative form will

improve chemical characterization in tandem mass spectrometry experiments and opens up enormous flexibility to the user.

\section{ACKNOWLEDGEMENTS}

This research was supported by the UF College of Liberal Arts and Sciences, the Office of Research, and the Department of Chemistry. The authors would like to thank Dr. Christian Berg and Dr. Melvin Park of Bruker Daltonics for their assistance developing the ion/ion reaction capabilities. We also acknowledge high resolution microscope imaging services provided by the University of Florida Center for Translational Research in Neurodegenerative Disease (CTRND). 


\section{REFERENCES}

1. Fahy, E.; Subramaniam, S.; Brown, H. A.; Glass, C. K.; Merrill, A. H., Jr.; Murphy, R. C.; Raetz, C. R.; Russell, D. W.; Seyama, Y.; Shaw, W.; Shimizu, T.; Spener, F.; van Meer, G.; VanNieuwenhze, M. S.; White, S. H.; Witztum, J. L.; Dennis, E. A., A comprehensive classification system for lipids. J Lipid Res 2005, 46 (5), 839-61.

2. Sud, M.; Fahy, E.; Cotter, D.; Brown, A.; Dennis, E. A.; Glass, C. K.; Merrill, A. H.; Murphy, R. C.; Raetz, C. R. H.; Russell, D. W.; Subramaniam, S.; A, LMSD: LIPID MAPS structure database. Nucleic Acids Res. 2007, 35 (1), D527-D532.

3. Liebisch, G.; Vizcaíno, J. A.; Köfeler, H.; Trötzmüller, M.; Griffiths, W. J.; Schmitz, G.; Spener, F.; Wakelam, M. J., Shorthand notation for lipid structures derived from mass spectrometry. J Lipid Res 2013, 54 (6), 1523-30.

4. Liebisch, G.; Ejsing, C. S.; Ekroos, K., Identification and annotation of lipid species in metabolomics studies need improvement. Clinical Chemistry 2015, 61 (12), 1542-1544.

5. Pauling, J. K.; Hermansson, M.; Hartler, J.; Christiansen, K.; Gallego, S. F.; Peng, B.; Ahrends, R.; Ejsing, C. S., Proposal for a common nomenclature for fragment ions in mass spectra of lipids. PLoS One 2017, 12 (11), e0188394.

6. McDonnell, L. A.; Heeren, R. M. A., Imaging mass spectrometry. Mass Spectrometry Reviews 2007, 26 (4), 606-643.

7. Norris, J. L.; Caprioli, R. M., Imaging Mass Spectrometry: A New Tool for Pathology in a Molecular Age. Proteomics. Clinical Applications 2013.

8. Wu, C. P.; Dill, A. L.; Eberlin, L. S.; Cooks, R. G.; Ifa, D. R., Mass spectrometry imaging under ambient conditions. Mass Spectrometry Reviews 2013, 32 (3), 218-243.

9. Kertesz, V.; Van Berkel, G. J., Liquid Microjunction Surface Sampling Coupled with HighPressure Liquid Chromatography-Electrospray Ionization-Mass Spectrometry for Analysis of Drugs and Metabolites in Whole-Body Thin Tissue Sections. Analytical Chemistry 2010, 82 (14), 5917-5921.

10. Van Berkel, G. J.; Kertesz, V., Continuous-flow liquid microjunction surface sampling probe connected on-line with high-performance liquid chromatography/mass spectrometry for spatially resolved analysis of small molecules and proteins. Rapid Communications in Mass Spectrometry 2013, 27 (12), 1329-1334.

11. Griffiths, R. L.; Cooper, H. J., Direct Tissue Profiling of Protein Complexes: Toward Native Mass Spectrometry Imaging. Analytical Chemistry 2016, 88 (1), 606-609.

12. Ryan, D. J.; Nei, D.; Prentice, B. M.; Rose, K. L.; Caprioli, R. M.; Spraggins, J. M., Protein identification in imaging mass spectrometry through spatially targeted liquid microextractions. Rapid Communications in Mass Spectrometry 2018, 32 (5), 442-450.

13. Wu, Q.; Huang, Z.; Wang, Y.; Zhang, Z.; Lu, H., Absolute quantitative imaging of sphingolipids in brain tissue by exhaustive liquid microjunction surface sampling-liquid chromatography-mass spectrometry. Journal of Chromatography A 2020, 1609, 460436.

14. Cornett, D. S.; Frappier, S. L.; Caprioli, R. M., MALDI-FTICR imaging mass spectrometry of drugs and metabolites in tissue. Analytical Chemistry 2008, 80 (14), 5648-5653.

15. Zemski Berry, K. A. H., Joseph A.; Barkley, Robert A.; Spraggins, Jeffery M.; Caprioli, Richard M.; Murphy, Robert C., MALDI imaging of lipid biochemistry in tissues by mass spectrometry. Chemical Reviews 2011, 111 (10), 6491-6512.

16. Bowman, A. P.; Blakney, G. T.; Hendrickson, C. L.; Ellis, S. R.; Heeren, R. M. A.; Smith, D. F., Ultra-high mass resolving power, mass accuracy, and dynamic range MALDI mass spectrometry imaging by 21-T FT-ICR MS. Anal Chem 2020, 92 (4), 3133-3142. 
17. McLean, J. A.; Ridenour, W. B.; Caprioli, R. M., Profiling and imaging of tissues by imaging ion mobility-mass spectrometry. Journal of Mass Spectrometry 2007, 42 (8), 10991105.

18. Stauber, J.; MacAleese, L.; Franck, J.; Claude, E.; Snel, M.; Kaletas, B.; Wiel, I. M. V. D.; Wisztorski, M.; Fournier, I.; Heeren, R. M. A., On-tissue protein identification and imaging by MALDI-ion mobility mass spectrometry. Journal of the American Society for Mass Spectrometry 2010, 21 (3), 338-347.

19. Xu, L.; Kliman, M.; Forsythe, J.; Korade, Z.; Hmelo, A.; Porter, N.; McLean, J., Profiling and Imaging Ion Mobility-Mass Spectrometry Analysis of Cholesterol and 7-

Dehydrocholesterol in Cells Via Sputtered Silver MALDI. Journal of the American Society for Mass Spectrometry 2015, 26 (6), 924-933.

20. Sans, M.; Feider, C. L.; Eberlin, L. S., Advances in mass spectrometry imaging coupled to ion mobility spectrometry for enhanced imaging of biological tissues. Current Opinion in Chemical Biology 2018, 42, 138-146.

21. Spraggins, J. M.; Djambazova, K. V.; Rivera, E. S.; Migas, L. G.; Neumann, E. K.; Fuetterer, A.; Suetering, J.; Goedecke, N.; Ly, A.; Van de Plas, R.; Caprioli, R. M., HighPerformance Molecular Imaging with MALDI Trapped Ion-Mobility Time-of-Flight (timsTOF) Mass Spectrometry. Analytical Chemistry 2019, 91 (22), 14552-14560.

22. Fu, T.; Oetjen, J.; Chapelle, M.; Verdu, A.; Szesny, M.; Chaumot, A.; Degli-Esposti, D.; Geffard, O.; Clément, Y.; Salvador, A.; Ayciriex, S., In situ isobaric lipid mapping by MALDI-Ion Mobility Separation-Mass Spectrometry Imaging. Journal of Mass Spectrometry 2020, $n / a(\mathrm{n} / \mathrm{a}), \mathrm{e} 4531$.

23. Burnum, K. E.; Tranguch, S.; Mi, D.; Daikoku, T.; Dey, S. K.; Caprioli, R. M., Imaging mass spectrometry reveals unique protein profiles during embryo implantation. Endocrinology 2008, 149 (7), 3274-3278.

24. Perdian, D. C.; Lee, Y. J., Imaging MS methodology for more chemical information in less data acquisition time utilizing a hybrid linear ion trap-orbitrap mass spectrometer. Analytical Chemistry 2010, 82 (22), 9393-9400.

25. Reich, R. F. Quantitative imaging of cocaine and its metabolites in brain tissue by matrixassisted laser desorption/ionization linear ion trap tandem mass spectrometry. University of Florida 2010.

26. Feenstra, A. D.; Hansen, R. L.; Lee, Y. J., Multi-matrix, dual polarity, tandem mass spectrometry imaging strategy applied to a germinated maize seed: toward mass spectrometry imaging of an untargeted metabolome. Analyst 2015, 140 (21), 7293-7304.

27. Prentice, B. M.; McMillen, J. C.; Caprioli, R. M., Multiple TOF/TOF events in a single laser shot for multiplexed lipid identifications in MALDI imaging mass spectrometry. International Journal of Mass Spectrometry 2019, 437, 30-37.

28. Murphy, R. C.; Axelsen, P. H., Mass spectrometric analysis of long-chain lipids. Mass Spectrom. Rev. 2011, 30 (4), 579-599.

29. McLuckey, S. A.; Mentinova, M., Ion/neutral, ion/electron, ion/photon, and ion/ion interactions in tandem mass spectrometry: do we need them all? Are they enough? Journal of the American Society for Mass Spectrometry 2011, 22 (1), 3-12.

30. Jackson, S.; Wang, H.-Y. J.; Woods, A., In situ structural characterization of phosphatidylcholines in brain tissue using MALDI-MS/MS. Journal of the American Society for Mass Spectrometry 2005, 16 (12), 2052-2056. 
31. Manier, M.; Reyzer, M.; Goh, A.; Dartois, V.; Via, L.; Barry, C.; Caprioli, R., Reagent precoated targets for rapid in-tissue derivatization of the anti-tuberculosis drug isoniazid followed by MALDI imaging mass spectrometry. Journal of the American Society for Mass Spectrometry 2011, 22 (8), 1409-1419.

32. Shariatgorji, M.; Nilsson, A.; Kallback, P.; Karlsson, O.; Zhang, X. Q.; Svenningsson, P.; Andren, P. E., Pyrylium Salts as Reactive Matrices for MALDI-MS Imaging of Biologically Active Primary Amines. Journal of the American Society for Mass Spectrometry 2015, 26 (6), 934-939.

33. Bednarik, A.; Bolsker, S.; Soltwisch, J.; Dreisewerd, K., An On-Tissue Paterno-Buchi Reaction for Localization of Carbon-Carbon Double Bonds in Phospholipids and Glycolipids by Matrix-Assisted Laser-Desorption-Ionization Mass-Spectrometry Imaging. Angew. Chem. Int. Ed. Engl. 2018, 57 (37), 12092-12096.

34. Wäldchen, F.; Spengler, B.; Heiles, S., Reactive matrix-assisted laser desorption/ionization mass spectrometry imaging using an intrinsically photoreactive Paternò-Büchi matrix for double-bond localization in isomeric phospholipids. Journal of the American Chemical Society 2019, 141 (30), 11816-11820.

35. Bednařík, A.; Preisler, J.; Bezdeková, D.; Machálková, M.; Hendrych, M.; Navrátilová, J.; Knopfová, L.; Moskovets, E.; Soltwisch, J.; Dreisewerd, K., Ozonization of Tissue Sections for MALDI MS Imaging of Carbon-Carbon Double Bond Positional Isomers of Phospholipids. Analytical Chemistry 2020, 92 (9), 6245-6250.

36. Paine, M. R. L.; Poad, B. L. J.; Eijkel, G. B.; Marshall, D. L.; Blanksby, S. J.; Heeren, R. M. A.; Ellis, S. R., Mass spectrometry imaging with isomeric resolution enabled by ozoneinduced dissociation. 2018, 57 (33), 10530-10534.

37. Born, M.-E. N.; Prentice, B. M., Structural elucidation of phosphatidylcholines from tissue using electron induced dissociation. International Journal of Mass Spectrometry 2020, 452, 116338.

38. Klein, D. R.; Feider, C. L.; Garza, K. Y.; Lin, J. Q.; Eberlin, L. S.; Brodbelt, J. S., Desorption Electrospray Ionization Coupled with Ultraviolet Photodissociation for Characterization of Phospholipid Isomers in Tissue Sections. Anal. Chem. 2018, 90 (17), 10100-10104.

39. Stephenson, J. L., Jr.; McLuckey, S. A., Ion/ion reactions in the gas phase: proton transfer reactions involving multiply-charged proteins. Journal of the American Chemical Society 1996, 118, 7390-7397.

40. Wells, J. M.; Chrisman, P. A.; McLuckey, S. A., Formation and characterization of proteinprotein complexes in vacuo. Journal of the American Chemical Society 2003, 125 (24), 72387249.

41. Webb, I. K.; Mentinova, M.; McGee, W. M.; McLuckey, S. A., Gas-phase intramolecular protein crosslinking via ion/ion reactions: ubiquitin and a homobifunctional sulfo-NHS ester. Journal of the American Society for Mass Spectrometry 2013, 24, 733-743.

42. Laszlo, K. J.; Bush, M. F., Analysis of Native-Like Proteins and Protein Complexes Using Cation to Anion Proton Transfer Reactions (CAPTR). Journal of the American Society for Mass Spectrometry 2015, 26 (12), 2152-2161.

43. Laszlo, K. J.; Munger, E. B.; Bush, M. F., Folding of Protein Ions in the Gas Phase after Cation-to-Anion Proton-Transfer Reactions. Journal of the American Chemical Society 2016, 138 (30), 9581-9588. 
44. Carvalho, V. V.; See Kit, M. C.; Webb, I. K., Ion Mobility and Gas-Phase Covalent Labeling Study of the Structure and Reactivity of Gaseous Ubiquitin Ions Electrosprayed from Aqueous and Denaturing Solutions. Journal of the American Society for Mass Spectrometry 2020, 31 (5), 1037-1046.

45. Newton, K. A.; He, M.; Amunugama, R.; McLuckey, S. A., Selective cation removal from gaseous polypeptide ions: proton vs. sodium ion abstraction via ion/ion reactions. Physical Chemistry Chemical Physics 2004, 6, 2710-2717.

46. Gunawardena, H. P.; O'Hair, R. A. J.; McLuckey, S. A., Selective disulfide bond cleavage in gold(I) cationized polypeptide ions formed via gas-phase ion/ion cation switching. Journal of Proteome Research 2006, 5 (9), 2087-2092.

47. Han, H.; McLuckey, S. A., Selective covalent bond formation in polypeptide ions via gasphase ion/ion reaction chemistry. Journal of the American Chemical Society 2009, 131 (36), 12884-12885.

48. Hassell, K. M.; Stutzman, J. R.; McLuckey, S. A., Gas-phase bioconjugation of peptides via ion/ion charge inversion: Schiff base formation on the conversion of cations to anions. Analytical Chemistry 2010, 82 (5), 1594-1597.

49. Mentinova, M.; McLuckey, S. A., Intra- and inter-molecular cross-linking of peptide ions in the gas phase: reagents and conditions. Journal of the American Society for Mass Spectrometry 2011, 22 (5), 912-921.

50. Stutzman, J. R.; McLuckey, S. A., Ion/ion reactions of MALDI-derived peptide ions increased sequence coverage via covalent and electrostatic modification upon charge inversion. Analytical Chemistry 2012, 84, 10679-10685.

51. McGee, W. M.; McLuckey, S. A., The ornithine effect in peptide cation dissociation. Journal of Mass Spectrometry 2013, In Press.

52. Prentice, B. M.; McGee, W. M.; Stutzman, J. R.; McLuckey, S. A., Strategies for the gas phase modification of cationized arginine via ion/ion reactions. International Journal of Mass Spectrometry 2013, 354, 211-218.

53. Prentice, B. M.; Stutzman, J. R.; McLuckey, S. A., Reagent cluster anions for multiple gasphase covalent modifications of peptide and protein cations. Journal of the American Society for Mass Spectrometry 2013, 24, 1045-1052.

54. Prentice, B. M.; Gilbert, J. D.; Stutzman, J. R.; Forrest, W. P.; McLuckey, S. A., Gas-phase reactivity of carboxylic acid functional groups with carbodiimides. Journal of the American Society for Mass Spectrometry 2013, 24 (1), 30-37.

55. Herron, W. J.; Goeringer, D. E.; McLuckey, S. A., Ion-ion reactions in the gas phase: proton transfer reactions of protonated pyridine with multiply charged oligonucleotide anions. Journal of the American Society for Mass Spectrometry 1995, 6, 529-532.

56. McLuckey, S. A.; Wu, J.; Bundy, J. L.; Stephenson, J. L., Jr.; Hurst, G. B., Oligonucleotide mixture analysis via electrospray and ion/ion reactions in a quadrupole ion trap. Analytical Chemistry 2002, 74, 976-984.

57. Stutzman, J. R.; Blanksby, S. J.; McLuckey, S. A., Gas-Phase Transformation of Phosphatidylcholine Cations to Structurally Informative Anions via Ion/Ion Chemistry. Analytical Chemistry 2013, 85 (7), 3752-3757.

58. Rojas-Betancourt, S.; Stutzman, J. R.; Londry, F. A.; Blanksby, S. J.; McLuckey, S. A., Gas-Phase Chemical Separation of Phosphatidylcholine and Phosphatidylethanolamine Cations via Charge Inversion Ion/Ion Chemistry. Analytical Chemistry 2015, 87 (22), 1125511262. 
59. Randolph, C. E.; Foreman, D. J.; Betancourt, S. K.; Blanksby, S. J.; McLuckey, S. A., Gasphase ion/ion reactions involving tris-phenanthroline alkaline earth metal complexes as charge inversion reagents for the identification of fatty acids. Analytical Chemistry 2018, 90 (21), 12861-12869.

60. Randolph, C. E.; Blanksby, S. J.; McLuckey, S. A., Toward Complete Structure Elucidation of Glycerophospholipids in the Gas Phase through Charge Inversion Ion/Ion Chemistry. Analytical Chemistry 2020, 92 (1), 1219-1227.

61. McLuckey, S. A.; Huang, T. Y., Ion/ion reactions: new chemistry for analytical MS. Analytical Chemistry 2009, 81 (21), 8669-8676.

62. Prentice, B. M.; McLuckey, S. A., Gas-phase ion/ion reactions of peptides and proteins: acid/base, redox, and covalent chemistries. Chemical Communications 2013, 49 (10), 947965.

63. Hankin, J. A.; Barkley, R. M.; Murphy, R. C., Sublimation as a method of matrix application for mass spectrometric imaging. Journal of the American Society for Mass Spectrometry 2007, 18 (9), 1646-1652.

64. Thomas, A.; Charbonneau, J.; Fournaise, E.; Chaurand, P., Sublimation of new matrix candidates for high spatial resolution imaging mass spectrometry of lipids: enhanced information in both positive and negative polarities after 1,5-diaminonapthalene deposition. Analytical Chemistry 2012, 84 (4), 2048-2054.

65. Kaplan, D. A.; Hartmer, R.; Speir, J. P.; Stoermer, C.; Gumerov, D.; Easterling, M. L.; Brekenfeld, A.; Kim, T.; Laukien, F.; Park, M. A., Electron transfer dissociation in the hexapole collision cell of a hybrid quadrupole-hexapole Fourier transform ion cyclotron resonance mass spectrometer. Rapid Communications in Mass Spectrometry 2008, 22 (3), 271-278.

66. Gilbert, J. D.; Prentice, B. M.; McLuckey, S. A., Ion/Ion Reactions with "Onium" Reagents: An Approach for the Gas-phase Transfer of Organic Cations to Multiply-Charged Anions. Journal of the American Society for Mass Spectrometry 2015, 26 (5), 818-825.

67. Bu, J. X.; Fisher, C. M.; Gilbert, J. D.; Prentice, B. M.; McLuckey, S. A., Selective Covalent Chemistry via Gas-Phase Ion/ion Reactions: An Exploration of the Energy Surfaces Associated with N-Hydroxysuccinimide Ester Reagents and Primary Amines and Guanidine Groups. Journal of the American Society for Mass Spectrometry 2016, 27 (6), 1089-1098.

68. Vance, D. E.; Vance, J. E., CHAPTER 8 - Phospholipid biosynthesis in eukaryotes. In Biochemistry of Lipids, Lipoproteins and Membranes (Fifth Edition), Vance, D. E.; Vance, J. E., Eds. Elsevier: San Diego, 2008; pp 213-244.

69. Luginbühl, M.; Young, R. S. E.; Stoeth, F.; Weinmann, W.; Blanksby, S. J.; Gaugler, S., Variation in the Relative Isomer Abundance of Synthetic and Biologically Derived Phosphatidylethanols and Its Consequences for Reliable Quantification. Journal of Analytical Toxicology 2020.

70. Berdeaux, O.; Juaneda, P.; Martine, L.; Cabaret, S.; Bretillon, L.; Acar, N., Identification and quantification of phosphatidylcholines containing very-long-chain polyunsaturated fatty acid in bovine and human retina using liquid chromatography/tandem mass spectrometry. $J$ Chromatogr A 2010, 1217 (49), 7738-48. 